\title{
Waxes in asphaltenes of crude oils and wax deposits
}

\author{
Yulia M. Ganeeva $^{1,2} \cdot$ Tatiana N. Yusupova ${ }^{1,2} \cdot$ Gennady V. Romanov $^{1,2}$
}

Received: 29 January 2016/Published online: 12 July 2016

(c) The Author(s) 2016. This article is published with open access at Springerlink.com

\begin{abstract}
Composition and molecular mass distribution of $n$-alkanes in asphaltenes of crude oils of different ages and in wax deposits formed in the borehole equipment were studied. In asphaltenes, $n$-alkanes from $\mathrm{C}_{12}$ to $\mathrm{C}_{60}$ were detected. The high molecular weight paraffins in asphaltenes would form a crystalline phase with a melting point of $80-90{ }^{\circ} \mathrm{C}$. The peculiarities of the redistribution of high molecular paraffin hydrocarbons between oil and the corresponding wax deposit were detected. In the oils, the high molecular weight paraffinic hydrocarbons $\mathrm{C}_{50}-\mathrm{C}_{60}$ were found, which were not practically detected in the corresponding wax deposits.
\end{abstract}

Keywords Waxes - Asphaltenes · Hydrocarbon composition · Crude oil · Wax deposit

\section{Introduction}

Waxes and asphaltenes are the most important constituents of crude oils because they have a great influence on crude oil properties. Waxes are a complex mixture of solid (at ambient temperature) hydrocarbons which consist mainly of paraffin hydrocarbons with a small amount of

Yulia M. Ganeeva

yuyand@yandex.ru

1 A.E. Arbuzov Institute of Organic and Physical Chemistry, Kazan Scientific Center, Russian Academy of Sciences, 8 Arbuzov St., Kazan, Russian Federation 420088

2 Institute of Geology and Petroleum Technologies, Kazan (Volga region) Federal University, 18 Kremlyovskaya St., Kazan, Russian Federation 420008

Edited by Yan-Hua Sun naphthenic and aromatic hydrocarbons as well as polar compounds. There are two general classes of petroleum waxes. Waxes that are composed primarily of normal alkanes (n-alkanes) with a chain length of $\mathrm{C}_{18}-\mathrm{C}_{30}$ and crystallize in large flat plates (macrocrystalline structures) with a melting point of $40-60{ }^{\circ} \mathrm{C}$ are referred to as paraffin waxes (Jowett 1984). Waxes, which consist primarily of the higher molecular weight $n$-alkanes within $\mathrm{C}_{30}-\mathrm{C}_{60}$, with a high share of iso-paraffins and naphthenes, and have much higher melting point ranges (above $60-90{ }^{\circ} \mathrm{C}$ ), are referred to as microcrystalline waxes. According to Musser and Kilpatrick (1998), paraffinic and microcrystalline waxes have molecular weight ranges of 350-600 and 300-2500, respectively.

The ratio of paraffinic to microcrystalline waxes in oils depends on origin of oils (Tissot and Welte 1978; Musser and Kilpatrick 1998; Philp 2004; Fazeelat and Saleem 2007). However, in most cases, the higher molecular weight paraffin hydrocarbons (microcrystalline type) are present in very low concentrations or are absent in produced oils. This is due to their low mobility and limited solubility in crude oil. As a result, these components remain in the reservoir rocks or precipitate out in borehole equipment when the temperature and pressure change. It was demonstrated repeatedly that high molecular weight $n$ alkanes were concentrated in solid deposits formed in well equipment and pipelines (Philp et al. 1995; Chouparova et al. 2004). Moreover, the concentrations of high molecular weight paraffin hydrocarbons in oils, which are determined by high temperature gas chromatography (HTGC, one of the main methods for investigating hydrocarbon composition of oils) (Lipsky and Duffy 1986; Hawthorne and Miller 1987), are underestimated because of the poor solubility of the high molecular weight hydrocarbons in the solvent and the difficulty in eluting of 
such high boiling components even at $440{ }^{\circ} \mathrm{C}$, resulting in the bias of response toward the shorter-chain homologs (Philp et al. 1995).

Asphaltenes are the heaviest and most polar compounds in crude oils with the highest aromaticity and polarity. They consist of fused polynuclear aromatic systems, heteroatoms ( $\mathrm{S}, \mathrm{N}$, and $\mathrm{O}$ ), alkyl chains, and heavy metals (e.g. Ni, V). Asphaltenes are defined according to their solubility, i.e., as the fraction of the crude oil which is soluble in toluene and precipitates in low boiling point alkanes ( $n$-pentane, $n$-heptane). Two of the representative structures for the asphaltene molecules belong to the "island" and "archipelago" structures (Groenzin and Mullins 2000; Acevedo et al. 2007). According to "island" structure, the most dominant part of the molecule is a planar polycyclic aromatic system containing on average 7 aromatic rings, and this aromatic system has poor alkyl substitution. The mean molecular weight for "island" asphaltenes is 750 with a distribution 500-1000, and the mean size is $2 \mathrm{~nm}$ (Mullins et al. 2012). The "archipelago" model (Acevedo et al. 2007; Strausz et al. 2008) represents several fused ring systems that are interconnected by alkyl chains. These two molecular structures probably coexist, and the debate is now centered on their proportions and specific roles in an asphaltene mixture.

As can be seen, asphaltenes and waxes differ greatly in chemical properties from each other and from other oil fractions. Asphaltenes are the most aromatic and polar fraction, waxes-most aliphatic and nonpolar. However, despite these differences, these two oil fractions are similar in that they have a high molecular weight, aggregate or associate in solutions, and have a limited solubility in crude oil. The waxes and asphaltenes have a dramatic influence on the properties of crude oil and can cause problems related to crystallization and aggregation, respectively. Changes in pressure, oil composition, and temperature often induce paraffin crystallization and/or asphaltene flocculation and precipitation. Wax- and asphaltene-related problems include solid deposits, stabilization of a water-oil emulsion, and sludge production. Determination of wax and asphaltene contents is a routine analytical requirement for crude oil quality control. In order to study the composition and properties of waxes and asphaltenes, they are isolated from oil by specially developed procedures. In general, the asphaltenes are isolated from oils first; waxes are isolated from deasphalted oil. In other words, the waxes are isolated from the oil system from which the asphaltenes have been removed beforehand [from maltenes (Branthaver et al. 1983; Elsharkawy et al. 2000; Fazeelat 2006; Alcazar-Vara and Buenrostro-Gonzalez 2011) or saturates (Yang and Kilpatrick 2005; Lu et al. 2008)]. However, the traditional methods used to isolate asphaltenes by adding 40 volumes in excess of low boiling point paraffin hydrocarbons can produce a fraction which is contaminated with a significant amount of waxes (Chouparova and Philp 1998; Thanh et al. 1999; Liao et al. 2006; Acevedo et al. 2009; Coto et al. 2011). The presence of paraffin hydrocarbons in asphaltenes can be explained by their coprecipitation as a result of low solubility in low molecular weight $n$-alkanes (Thanh et al. 1999; Coto et al. 2011), by interaction between the alkyl lateral chains $\left(\mathrm{C}_{7}-\mathrm{C}_{10}\right)$ of asphaltenes with high molecular weight $n$-alkanes (Garcia and Carbognani 2001; Stachowiak et al. 2005; Ganeeva et al. 2014), and by their adsorption and/or occlusion inside asphaltene aggregates (Liao et al. 2005, 2006; Acevedo et al. 2009; Gray et al. 2011). Now, it is well-known that the asphaltenes exist as three-dimensional aggregates due to the strong intermolecular forces such as hydrogen bonding and $\pi$-bonding (Murgich 2002) and even at very low concentration as $50-150 \mathrm{mg} / \mathrm{L}$ in a good solvent such as toluene (Mullins et al. 2012). The wax coprecipitation increases the apparent yield of asphaltenes, decreases the yield of waxes, and leads to incorrect determination of the composition and properties of asphaltenes and waxes, to provide misleading and ambiguous results in modeling and treatment programs. Methods for the separation of waxes from asphaltenes have been developed (Thanh et al. 1999; Schabron et al. 2012).

It is impossible to avoid the coprecipitation of high molecular paraffin hydrocarbons with asphaltenes under the standard procedure of oil deasphalting. This phenomenon can be used to concentrate the most high molecular paraffin hydrocarbons to study their composition and properties in some detail. Hence the goal of this paper is focused on an examination of the waxes in asphaltenes of different oils and corresponding solid deposits.

\section{Experimental}

Five crude oils (designated as oil 1-5) and three solid deposits (designated as deposit 3-5) were selected from oil fields of Russia and Kyrgyzstan (Table 1). The crude oils 1-3 were produced from oil reservoirs of different ages in the Samara region (Russia): Carboniferous (Bashkirian and Tournaisian stages) and Devonian periods, respectively. The crude oils 4 and 5 were produced from the giant Romashkinskoe oil field of Tatarstan (Russia) and the Maily-Su oil field (Kyrgyzstan), respectively. The solid deposits 3-5 formed in the borehole equipment during production of crude oils 3-5, respectively. Chemical composition, some properties of these crude oils and solid deposits, as well as the age of the oil reservoirs, from which the crude oils were produced, are shown in Table 1.

Asphaltenes were precipitated by a 40-fold excess dilution of the crude oil with petroleum ether (boiling point 
Table 1 Properties of crude oils and solid deposits

\begin{tabular}{|c|c|c|c|c|c|c|}
\hline Symbol & Resource & $\begin{array}{l}\text { Waxes, } \\
\text { wt } \%\end{array}$ & $\begin{array}{l}\text { Asphaltenes, } \\
\text { wt } \%\end{array}$ & $\begin{array}{l}\text { Density, } \\
\mathrm{g} / \mathrm{cm}^{3}\end{array}$ & $\begin{array}{l}\text { Viscosity, } \\
\text { cSt }\end{array}$ & $\begin{array}{l}T_{\text {wa }} \text { for crude oil } / T_{\text {melt }} \\
\text { for solid deposit, }{ }^{\circ} \mathrm{C}^{\mathrm{a}}\end{array}$ \\
\hline \multicolumn{7}{|l|}{ Crude oil } \\
\hline Crude oil 1 & $\begin{array}{l}\text { Russia, Samara region, Bashkirian stage } \\
\text { (Carboniferous period) }\end{array}$ & 3.6 & 0.3 & 0.7861 & 2.2 & \\
\hline Crude oil 2 & $\begin{array}{l}\text { Russia, Samara region, Tournaisian stage } \\
\text { (Carboniferous period) }\end{array}$ & 7.7 & 3.8 & 0.8551 & 16.2 & \\
\hline Crude oil 3 & Russia, Samara region, Devonian period & 25.0 & 1.4 & 0.9100 & 72.2 & 46.1 \\
\hline Crude oil 4 & Russia, Tatarstan, Devonian period & 6.0 & 4.7 & 0.9180 & 55.7 & $50.1^{\mathrm{b}}$ \\
\hline Crude oil 5 & Kyrgyzstan & 6.1 & 6.6 & 0.9100 & 48.9 & 30.4 \\
\hline \multicolumn{7}{|l|}{ Deposit } \\
\hline Deposit 3 & Russia, Samara region, Devonian period & 72.1 & 0.8 & & & 80.3 \\
\hline Deposit 4 & Russia, Tatarstan, Devonian period & 65.9 & 3.1 & & & 75.9 \\
\hline Deposit 5 & Kyrgyzstan & 49.4 & 6.6 & & & 72.4 \\
\hline
\end{tabular}

a $T_{\text {wa }}$ is the wax appearance temperature and $T_{\text {melt }}$ is the melting temperature

b The content of water in this crude oil is $19.8 \mathrm{wt} \%$. Other crude oils contain no water

$40-70{ }^{\circ} \mathrm{C}$ ). The precipitated asphaltenes were washed in a Soxhlet apparatus with petroleum ether until the filtrate was colorless. Then the asphaltenes in the filter were washed out with benzene, which was then evaporated. Waxes were isolated from the deasphalted resin-free crude oil according to the European standard method EN 12606-2. The deasphalted oil (maltenes) was adsorbed onto silica gels, previously activated at $120{ }^{\circ} \mathrm{C}$ overnight. After adsorption the silica gel was washed with a mixture of 3:1 petroleum ether/carbon tetrachloride, the obtained extract was then concentrated to yield resin-free oil. The resin-free oil was dissolved in a mixture of 1:1 acetone/benzene in the ratio of $1 \mathrm{~g}$ sample per $10 \mathrm{~mL}$ solvent and thereafter cooled to the temperature of $-20 \pm 1{ }^{\circ} \mathrm{C}$. The waxes present in the oil precipitated, and then they were washed by hot benzene and finally weighed after solvent removal. Resins with silica gels were washed off with a mixture of $1: 1$ benzene/isopropanol.

Asphaltenes and waxes from solid deposits were isolated similarly. It should be noted that before the study the solid deposits were purified from mechanical impurities.

Hydrocarbon composition of waxes was analyzed by gas chromatography (GC) on a Perkin-Elmer chromatograph with a flame-ionization detector in the mode of temperature programming from 20 to $400{ }^{\circ} \mathrm{C}$. PE-5ht capillary column (30 $\mathrm{m}$ long, $0.25 \mathrm{~mm}$ in internal diameter) and $5 \%$-phenil$95 \%$-methylpolysiloxane with a film thickness of $0.1 \mu \mathrm{m}$ were used as the stationary phase. The flow rate of the helium carrier gas was set at $2 \mathrm{~cm}^{3} / \mathrm{min}$. $1 \%$ solutions of the samples in carbon tetrachloride were prepared. The calibration was carried out using $n-\mathrm{C}_{20}$.

As was shown by Ganeeva et al. (2014), the $n$-alkanes dominate the chromatograms of oils, waxes, and asphaltenes; therefore, further we discuss only the molecular mass distribution (MMD) of $n$-alkanes in waxes, estimated by the method of internal normalization.

Thermal characterization was carried out with a C80 calorimeter (Setaram, France). The temperature calibration was performed using indium. The energy calibration was performed using the Joule effect method in the factory and checked by measuring the heat of fusion of naphthalene. Each sample $(5-10 \mathrm{mg})$ was first heated to $100^{\circ} \mathrm{C}$, held isothermally for $1 \mathrm{~min}$, and then cooled to ambient temperature at a rate of $1{ }^{\circ} \mathrm{C} / \mathrm{min}$. In order to delete any thermal history effects, two heating/cooling cycles were recorded, so that crystallization and melting properties were obtained from the second cycle. Measured thermal characteristics include temperatures and enthalpies of melting and crystallization of waxes. The temperature of melting $\left(T_{\text {melt }}\right)$ was determined as the extreme point (minima) on heat flow curves. The enthalpy of melting was calculated as the area defined by the heat flow curve and base line between the points of onset and end of the endothermic effect on the heat flow curve. The wax appearance temperature ( $\left.T_{\mathrm{wa}}\right)$ of crude oils was determined as the onset of an exothermic peak on the heat flow curves under cooling (Table 1). The experimental uncertainties in the measurements of temperatures and enthalpies were $\pm 0.5^{\circ} \mathrm{C}$ and $\pm 0.01 \mathrm{~J} / \mathrm{g}$, respectively.

\section{Results and discussion}

\subsection{High molecular weight paraffin hydrocarbons in oils}

It was found that the $n$-alkanes with a wide range of carbon numbers were present in oil asphaltenes, which were 
determined by GC (Fig. 1). In asphaltenes $1-3, n$-alkanes were present with a carbon number of 10-60; their MMDs were polymodal with clearly marked predominance of one of the modes at $\mathrm{C}_{16}-\mathrm{C}_{18}, \mathrm{C}_{12}-\mathrm{C}_{14}$, and $\mathrm{C}_{54}-\mathrm{C}_{56}$, respectively. In asphaltenes 4 , the $n$-alkanes had a carbon number of 20-54. MMD of these $n$-alkanes was bimodal with the dominating maximum at carbon numbers of 40-42. The asphaltenes 5 contained $n$-alkanes $\mathrm{C}_{20}-\mathrm{C}_{60}$, and their MMD was unimodal with the maxima at a carbon number of 52-54. It should be noted that all asphaltenes were black and shiny and nothing indicated that they contain paraffin hydrocarbons.

The presence of high molecular weight mode in MMD of $n$-alkanes in asphaltenes suggests that these coprecipitated paraffinic hydrocarbons can form a crystalline phase. Indeed, on the heat flow curves of the asphaltenes 3-5 at a temperature interval of $80-90{ }^{\circ} \mathrm{C}$, a well-resolved narrow (10-15 ${ }^{\circ} \mathrm{C}$ width) endothermic peak indicating the melting of the crystalline phase of waxes (Fig. 2) was observed. The heat flow curve of the asphaltenes 5 is not shown on Fig. 2 because the content of the crystalline phase of paraffin hydrocarbons in them was low (enthalpy of melting of the crystalline phase is only $2.5 \mathrm{~J} / \mathrm{g}$ ) and at the scale of figure, the effect of melting was not visible. Values of the enthalpy of melting of the crystalline phase in asphaltenes 3 and 4 were 119.6 and $108.4 \mathrm{~J} / \mathrm{g}$, respectively. In asphaltenes 1 and 2, in which the low molecular weight $n$-alkanes dominated, the crystalline phase was not observed.

A comparison was made between compositions of waxes coprecipitated with asphaltenes and waxes which were isolated from maltenes using acetone. In most cases, the isolation of waxes from crude oil was carried out using acetone by various modifications of the Burger method (Burger et al. 1981), when the waxes were isolated from maltenes (Branthaver et al. 1983; Elsharkawy et al. 2000; Fazeelat 2006; Alcazar-Vara and Buenrostro-Gonzalez 2011) or saturates (Yang and Kilpatrick 2005; Lu et al. 2008).

According to the GC data on waxes isolated from crude oils by the standard method, the low molecular weight $n$ alkanes with carbon atoms $<16$ and high molecular weight homologs with a carbon number $>50$ were absent (Fig. 3). The waxes from investigated oils contained $n$-alkanes $\mathrm{C}_{18}$ $\mathrm{C}_{48}$ and exhibited unimodal MMDs with maxima at $\mathrm{C}_{26}$ $\mathrm{C}_{28}$. It is evident that the waxes isolated from different oils by the standard method were almost the same, did not contain high molecular weight hydrocarbons, and did not characterize the peculiarities of hydrocarbon composition of oils studied. The MMDs of $n$-alkanes of waxes in asphaltenes and waxes isolated from crude oils by the standard method demonstrated (Figs. 1, 3) that in asphaltenes, there were $n$-alkanes with a wider range of carbon numbers of $12-60+$, their MMD was polymodal, and one of the maxima of MMD was shifted to higher molecular mass.

On the example of the oils from oil reservoirs of different ages in the Samara region, Russia (oils 1-3), it is shown that the MMDs of $n$-alkanes in the asphaltenes were quite different depending on the age of the oil reservoir from which the oils were produced (Fig. 1). So, in the asphaltenes of crude oil 1 taken from the Bashkirian stage (Carboniferous period), the main wide maximum of MMD was $\mathrm{C}_{16}-\mathrm{C}_{28}$. With an increase in the age of oil reservoirs (Tournaisian stage, Carboniferous period), the main maximum of MMD of $n$-alkanes in asphaltenes was shifted to low molecular weight $n$-alkanes $\mathrm{C}_{12}-\mathrm{C}_{13}$ (asphaltenes of oil 2) when the occurrence depth increased. In asphaltenes of oil 3 taken from greater depth (Devonian period), low weight molecular $n$-alkanes were practically absent and the main maximum of MMD was at carbon numbers of 54-56.

Most possibly, the presence of low molecular $n$-alkanes in the asphaltenes is caused by their being trapped by porous structure of asphaltenes, while the presence of high molecular weight homologs in asphaltenes is a result from coprecipitating when the standard procedure of deasphalting by low molecular weight $n$-alkanes is used. The decrease in the share of low molecular weight $n$-alkanes in asphaltenes with the increase of the age of oil reservoir may result from: (1) decrease in the share of low molecular weight $n$-alkanes in greater depth crude oils and/or (2) compression of asphaltene aggregates: when the occurrence depth of oil reservoirs increases, the asphaltene aggregates in oil become denser and their ability to occlude low molecular weight oil hydrocarbons reduces. The increase in the share of high molecular weight $n$-alkanes in asphaltene with increasing age of oil reservoir is explained by the increase in their share in the oils, from which asphaltenes are precipitated (Ganeeva et al. 2010).

Thus, asphaltenes contain paraffin hydrocarbons with a wide range of carbon numbers from 10 to 60 (depending on the composition of oil), and their MMD can depend on the structure of asphaltenes and hydrocarbon composition of oil. High molecular weight paraffin hydrocarbons in asphaltenes can form crystalline phases. The content and composition of waxes isolated from deasphalting resin-free oil do not represent the total content, and compositional features of all waxes present in crude oil. For a more complete study of the composition and properties of oil waxes, especially as regard to their most high molecular weight paraffins, an accurate study of the asphaltenes is required.

The phenomenon of coprecipitation of the most high molecular weight paraffin hydrocarbons with asphaltenes at the standard procedure of deasphalting was used by us for studying the redistribution of high molecular weight 

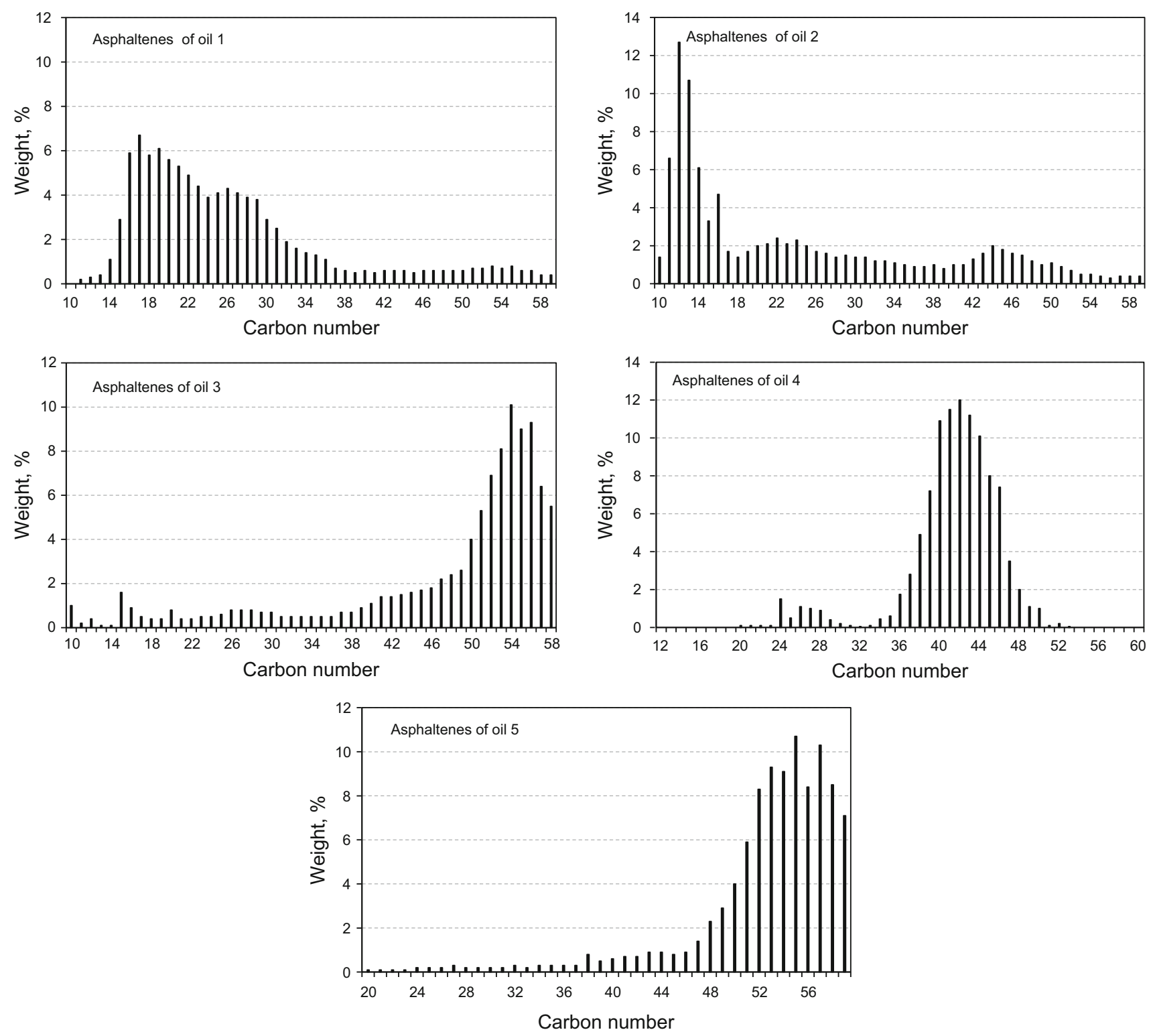

Fig. 1 MMD of $n$-alkanes in oil asphaltenes

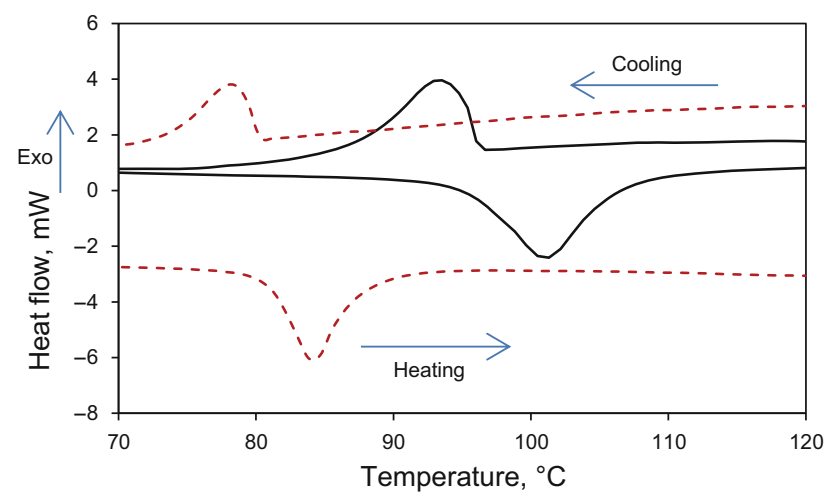

Fig. 2 Heat flow curves of asphaltenes from oils 3 (solid lines) and 4 (dashed lines) paraffin hydrocarbons between oils and solid deposits formed in well equipment during oil production. For this purpose, we studied the composition of paraffin hydrocarbons in corresponding solid deposits focusing on the study of waxes in asphaltenes from solid deposits.

\subsection{The composition and properties of waxes in wax deposits}

The solid deposit formed in producing wells, in borehole equipment, and pipelines is known to represent a complex mixture of waxes, asphaltenes, and resins along with trapped oil, water, and inorganic material. The amount and composition of the solid deposits are a function of 

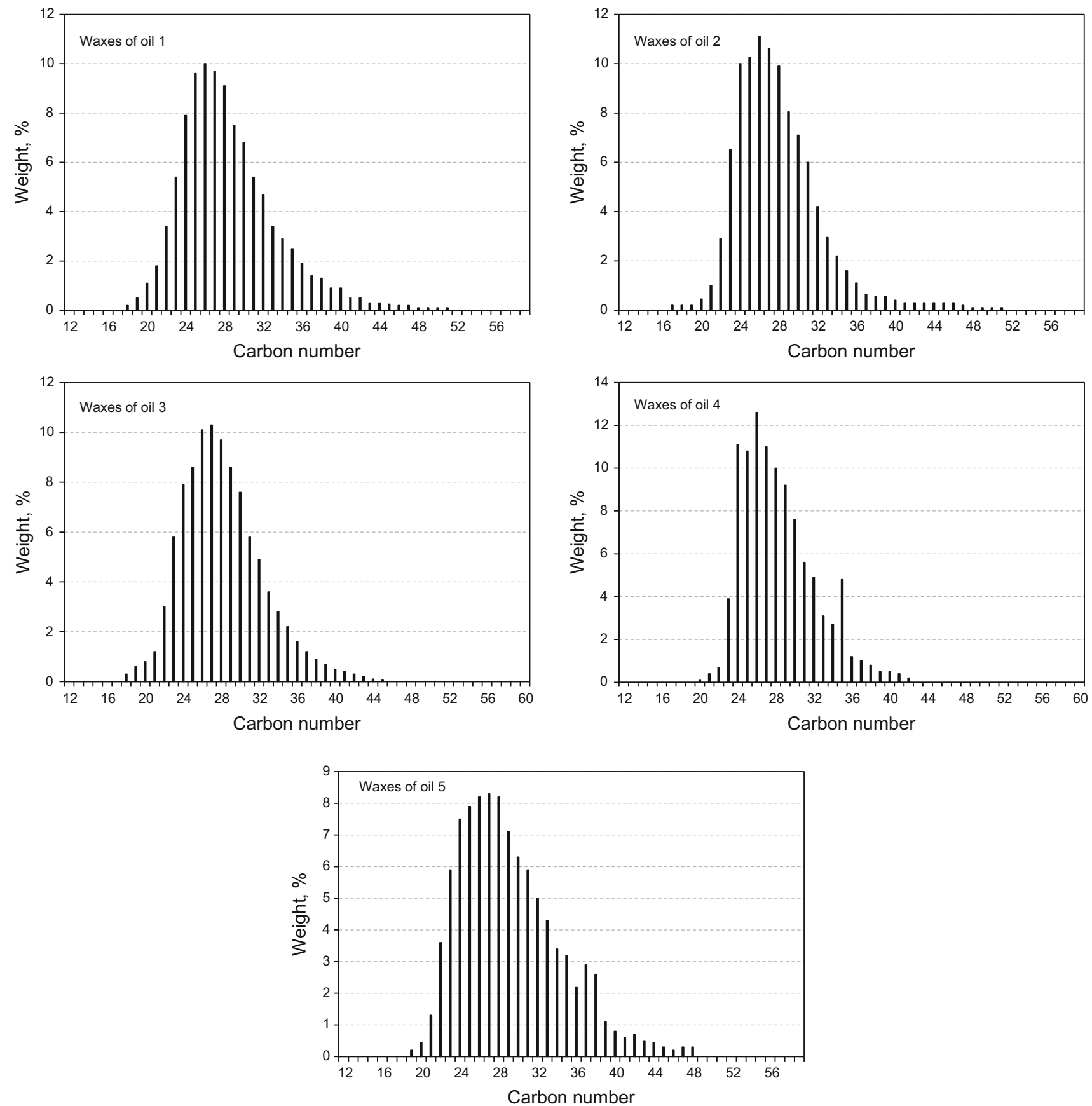

Fig. 3 MMD of $n$-alkanes in waxes of oils $1-5$

changing temperature, pressure, and oil composition during oil production (Leontaritis 1996; Chouparova et al. 2004). It is known that solid deposits produced from different depths of the same well vary in amount and composition: the closer to the surface the bigger the amount of solid deposits and the bigger the share of low molecular weight $n$-paraffin hydrocarbon (macrocrystalline waxes) in them. At greater depths, little solid deposit is formed, but it contains a high proportion of the most high molecular weight paraffin hydrocarbons (microcrystalline waxes) (Chouparova et al. 2004). Thus, it is believed that most unstable macro- and microcrystalline waxes may precipitate from oil and form the solid deposits at different depths in the well, in borehole equipment, and pipelines, and therefore high molecular weight hydrocarbons are practically absent in produced oils. This fact has been demonstrated repeatedly by comparative analyses of MMD of paraffin hydrocarbons in oils and in the corresponding solid 
deposits (Philp et al. 1995; Garcia 2001; Paso and Fogler 2004; Yang and Kilpatrick 2005). Since we have shown that the most high molecular weight paraffin hydrocarbons are concentrated in asphaltenes; then in order to study the peculiarities of redistribution of the most high molecular weight paraffin hydrocarbons between oil and solid deposit, we studied the composition of $n$-alkanes in asphaltenes of solid deposits and compared it with that of the corresponding oils.

The solid deposits studied were dark brown semi-solid materials, characterized by high melting point, and for this reason, they were classified as wax deposits (Table 1). It should be noted that asphaltenes isolated from the wax deposits were light brown and had a greasy consistency. This testified that asphaltenes were polluted by waxes.

According to calorimetry data on these asphaltenes, there was a crystalline phase of paraffin hydrocarbons with enough high melting temperatures from 80 to $90{ }^{\circ} \mathrm{C}$ and high enthalpies of melting 150-170 J/g (Fig. 4).

Asphaltenes were investigated with GC. Figure 5 shows the MMDs of $n$-alkanes in asphaltenes of the wax deposits 3,4 , and 5. As can be seen, asphaltenes of wax deposits contained $n$-alkanes with a carbon number of $16-60$ as the oil asphaltenes. The maxima of MMD of the $n$-alkanes in asphaltenes of wax deposit 3 was at 41-44, in asphaltenes of wax deposit 5 at $49-51$. The MMD of $n$-alkanes in asphaltenes of wax deposit 4 was bimodal with the maxima at $27-29$ and $40-42$.

A comparative analysis of the composition and thermal properties of paraffin hydrocarbons in asphaltenes of crude oils and the corresponding wax deposits shows that the asphaltenes of crude oils contain higher molecular weight paraffin hydrocarbons (Figs. 1, 5). Indeed, the maxima of MMD of $n$-alkanes in oil asphaltenes 3, 4, and 5 was at 54-56, 40-44, and 54-56 (Fig. 1), whereas the maxima of MMD of $n$-alkanes in corresponding wax deposit asphaltenes showed $n$-alkanes with a smaller number of carbon atoms with maxima at 41-43, 40-42, and 49-51,

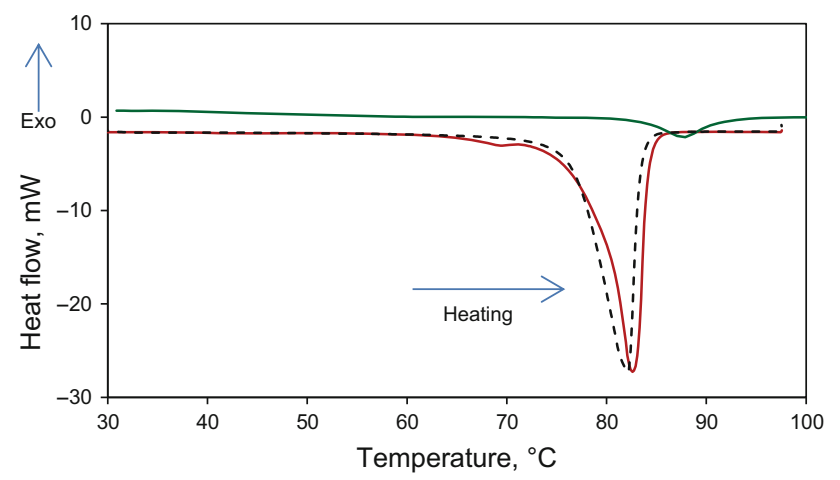

Fig. 4 Heat flow curves of asphaltenes from wax deposits 3 (green line), 4 (red solid line), and 5 (dashed line) respectively (Fig. 5). The temperatures of melting of waxes in oil asphaltenes $3-5$ were $101.2,85.2$, and $89.5^{\circ} \mathrm{C}$ while those in the corresponding asphaltenes of wax deposits were $88.1,81.4$, and $81.2^{\circ} \mathrm{C}$. The higher temperatures of melting of waxes in oil asphaltenes confirm the higher molecular weight composition of waxes in them.

Thus, it is found that in produced oil there are higher molecular weight paraffin hydrocarbons that are absent in the wax deposits formed in the borehole equipment during production of this crude oil. In other words, the highest
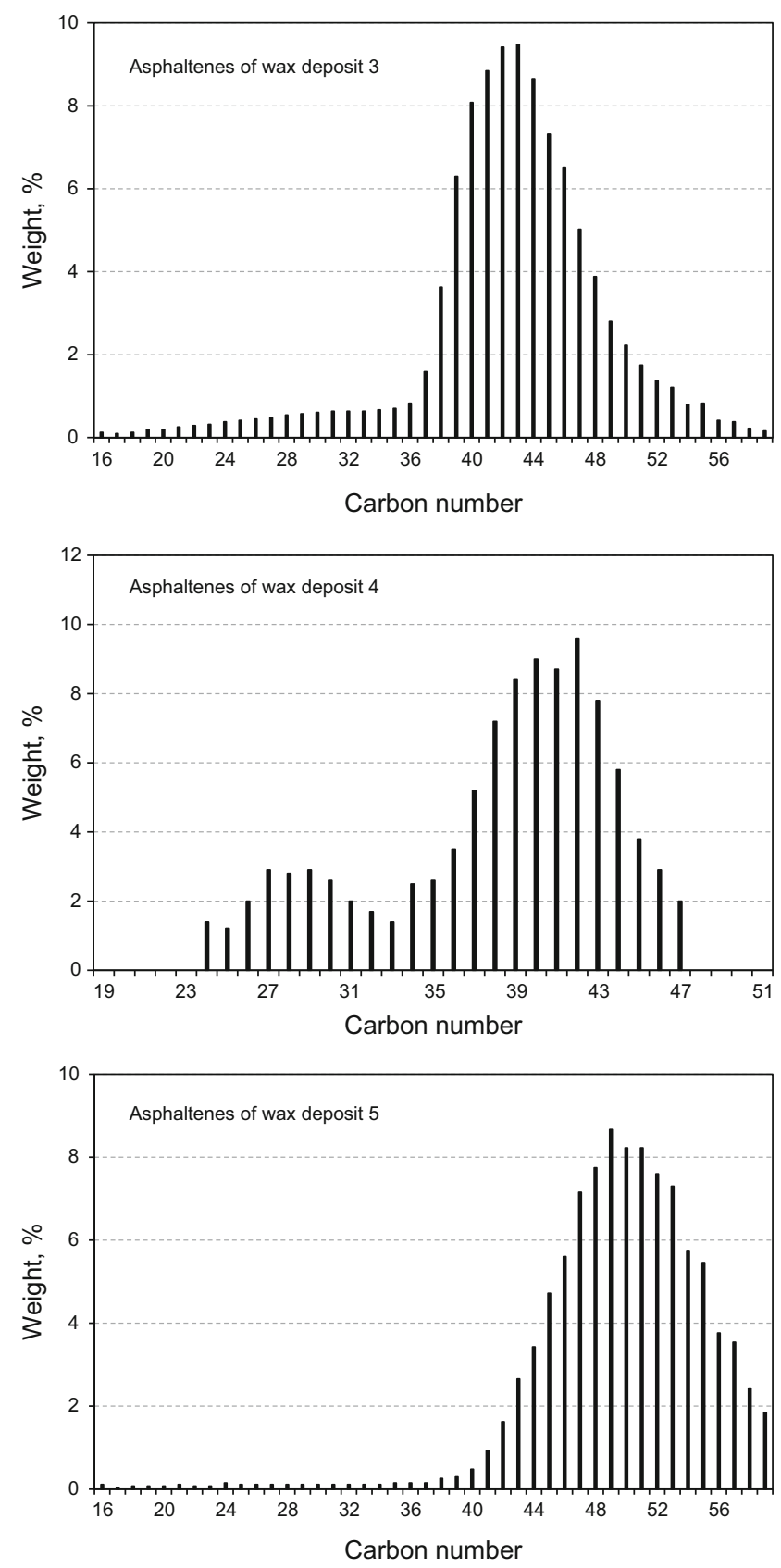

Fig. 5 MMD of $n$-alkanes in asphaltenes of wax deposits 3-5 
molecular weight $n$-alkanes do not precipitate out and remain dispersed in the oil. It should be noted that this fact is not surprising for mixture of individual $n$-alkanes in solvents and is predictable for crude oil. So, previously the polydispersity and cocrystallization of individual $n$-alkanes in solvents reduce the mass and high molecular weight homolog fraction in a deposit formed using a coldfinger apparatus (Senra et al. 2008). As to crude oils, the share of high molecular weight hydrocarbons in them is very low [a recurrence ratio of $\mathrm{C}_{n+1} / \mathrm{C}_{n}$ is approximately $0.7-0.8$ (Senra 2009)]; therefore, the $n$-alkanes that will crystallize out at the cloud point should not necessarily be the highest molecular weight $n$-alkanes present in the crude oil. However, it is known from papers (Philp et al. 1995; Garcia and Carbognani 2001; Paso and Fogler 2004; Yang and Kilpatrick 2005) that paraffin hydrocarbons in the wax deposits are higher molecular weight in comparison with those in the oil. The investigation of asphaltenes in which the highest molecular weight paraffin hydrocarbons are concentrated shows that indeed the wax deposit consists not the most high molecular weight hydrocarbons of crude oils. Evidently, more high molecular weight $n$-alkanes initiate the crystallizing of the more low molecular homologs causing their deposition from crude oil in a greater degree.

\section{Conclusions}

The research found that asphaltenes contain paraffin hydrocarbons with a wide MMD from 12 to 60. On the example of the oils of different ages from the Samara region, Russia, it is shown that the composition of paraffin hydrocarbons in asphaltenes depends on the age of the oil reservoir from which oil is produced. The higher the age of oil reservoir, the smaller the share of low molecular weight $n$-alkanes in asphaltenes. That may be due to the decrease in the share of low molecular weight $n$-alkanes in oil and the fact that with increasing depth of occurrence of the oil reservoir, the asphaltenes become denser and their ability to occlude low molecular weight hydrocarbons reduces. The increase in the share of high molecular weight $n$ alkanes in asphaltenes with an increase in the age of oil reservoir is explained by the increase in their share in the oil, from which asphaltenes are precipitated.

The higher molecular weight waxes may coprecipitate with asphaltenes and in some cases can form a crystalline phase in them with melting temperatures of $80-90{ }^{\circ} \mathrm{C}$. Therefore, the commonly used methods of determination of the content of waxes in oils (by acetone from maltenes or saturates) do not allow the investigation of the total content and composition of waxes of crude oil, especially their high molecular weight constituents.
The study of the composition of paraffin hydrocarbons in oil asphaltenes allowed identifying the peculiarities of redistribution of high molecular weight paraffin hydrocarbons between oil and wax deposits. In asphaltenes of oils higher molecular weight, $n$-alkanes are found in comparison with the corresponding wax deposits. This indicates that in the wax deposits not all high molecular weight paraffin hydrocarbons are concentrated. A part of higher molecular $n$-alkanes remains in oil and initiates crystallization of more low molecular weight homologs, causing their deposition from crude oil to a greater degree.

Thus, the performed study shows the need for a careful analysis of asphaltenes to determine the exact composition of paraffin hydrocarbons of oils, especially their high molecular weight constituents, and to detect the peculiarities of redistribution of high molecular weight paraffin hydrocarbons in crude oils.

Acknowledgments The work is performed according to the Russian Government Program of Competitive Growth of Kazan Federal University.

Open Access This article is distributed under the terms of the Creative Commons Attribution 4.0 International License (http://crea tivecommons.org/licenses/by/4.0/), which permits unrestricted use, distribution, and reproduction in any medium, provided you give appropriate credit to the original author(s) and the source, provide a link to the Creative Commons license, and indicate if changes were made.

\section{References}

Acevedo S, Castro A, Negrin JG, Fernandez A, Escobar G, Piscitelli V. Relations between asphaltene structures and their physical and chemical properties: the rosary-type structure. Energy Fuels. 2007;21(4):2165-75. doi:10.1021/ef070089v.

Acevedo S, Cordero JMT, Carrier H, Bouyssiere B, Lobinski R. Trapping of paraffin and other compounds by asphaltenes detected by laser desorption ionization-time of flight mass spectrometry (LDI-TOF MS): role of A1 and A2 asphaltene fractions in this trapping. Energy Fuels. 2009;23:842-8. doi:10. 1021/ef8007745.

Alcazar-Vara LA, Buenrostro-Gonzalez E. Characterization of the wax precipitation in Mexican crude oils. Fuel Process Technol. 2011;92:2366-74. doi:10.1016/j.fuproc.2011.08.012.

Branthaver JF, Thomas KR, Dorrence SM, Heppner RA, Ryan MJ. An investigation of waxes isolated from heavy oils produced from northwest asphalt ridge tar sands. Liq Fuels Technol. 1983;1:127-46.

Burger ED, Perkins TK, Striegler JH. Studies of wax deposition in the Trans-Alaska pipeline. J Pet Technol. 1981;33:1075-86. doi:10. 2118/8788-PA.

Chouparova E, Philp RP. Geochemical monitoring of waxes and asphaltenes in oils produced during the transition from primary to secondary water flood recovery. Org Geochem. 1998;29:449-61. doi:10.1016/S0146-6380(98)00066-7.

Chouparova E, Lanzirotti A, Feng H, Jones KV, Marinkovic N, Whitson C, Philp P. Characterization of petroleum deposits formed in a producing well by synchrotron radiation-based 
microanalysis. Energy Fuels. 2004;18:1199-212. doi:10.1021/ ef030108a.

Coto B, Martos C, Espada JJ, Robustillo MD, Merino-Garcia D, Pena JL. Study of new methods to obtain the $n$-paraffin distribution of crude oils and its application to the flow assurance. Energy Fuels. 2011;25:487-92. doi:10.1021/ef100987v.

Elsharkawy AM, Al-Sahhaf TA, Fanhim MA. Wax deposition from Middle East crudes. Fuel. 2000;79:1047-55. doi:10.1016/S00162361(99)00235-5.

Fazeelat TJ. Chemical composition and geochemical applications of waxes isolated from Pakistani crude oil. J Chem Soc Pak. 2006;26:187-90.

Fazeelat TJ, Saleem A. GC-FID analysis of wax paraffin from Khaskheli crude oil. J Chem Soc Pak. 2007;29:492-9.

Ganeeva YM, Foss TR, Yusupova TN, Romanov GV. Distribution of high-molecular-weight $n$-alkanes in paraffinic crude oils and asphaltene-resin-paraffin deposits. Pet Chem. 2010;50:17-22. doi:10.1134/S0965544110010020.

Ganeeva YM, Yusupova TN, Romanov GV, Bashkirtseva NY. Phase composition of asphaltenes. J Therm Anal Calorim. 2014;115:1593-600. doi:10.1007/s10973-013-3442-3.

Garcia MC. Paraffin deposition in oil production. In: SPE international symposium on oilfield chemistry, 13-16 February, Houston, TX, 2001. doi:10.2118/64992-MS.

Garcia MC, Carbognani L. Asphaltene-paraffin structural interactions: effect on crude oil stability. Energy Fuels. 2001;15:1021-7. doi:10.1021/ef0100303.

Gray MR, Tykwinski RR, Stryker JM, Tan X. Supramolecular assembly model for aggregation of petroleum asphaltenes. Energy Fuels. 2011;25:3125-34. doi:10.1021/ef200654p.

Groenzin H, Mullins OC. Molecular size and structure of asphaltenes from various sources. Energy Fuels. 2000;14:677-84. doi:10. 1021/ef990225z.

Hawthorne SB, Miller DJ. Analysis of commercial waxes using capillary supercritical fluid chromatography-mass spectrometry. J Chromatogr. 1987;388:397-409. doi:10.1016/S00219673(01)94500-5.

Jowett F. Petroleum waxes. In: Hobson GD, editor. Petroleum technology. New York: Wiley; 1984. p. 1021-42.

Leontaritis KJ. The asphaltene and wax deposition envelopes. Fuel Sci Technol Int. 1996;14:13-39.

Liao Z, Zhou H, Graciaa A, Chrostowka A, Creux P, Geng A. Adsorption/occlusion characteristics of asphaltenes: some implication for asphaltene structural features. Energy Fuels. 2005;19:180-6. doi:10.1021/ef049868r.

Liao Z, Geng A, Graciaa A, Creux P, Chrostowka A, Zhang Y. Different adsorption/occlusion properties of asphaltenes associated with their secondary evolution processes in oil reservoirs. Energy Fuels. 2006;20:1131-6. doi:10.1021/ef050355+.

Lipsky SR, Duffy ML. High temperature gas chromatography: the development of new aluminum clad flexible fused silica glass capillary columns coated with thermostable nonpolar phases.
Part 2. J High Resolut Chrom Chrom Commun. 1986;9:725-30. doi:10.1002/jhrc. 1240090702 .

Lu X, Kalman B, Redelius P. A new test method for determination of wax content in crude oils, residues and bitumens. Fuel. 2008;87:1543-51. doi:10.1016/j.fuel.2007.08.019.

Mullins OC, Sabbah H, Eyssautier J, Pomerantz AE, Barre L, Andrews AB, et al. Advances in asphaltene science and the YenMullins model. Energy Fuels. 2012;26:3986-4003. doi:10.1021/ ef300185p.

Murgich J. Intermolecular forces in aggregates of asphaltenes and resins. Pet Sci Technol. 2002;20:983-97.

Musser BJ, Kilpatrick PK. Molecular characterization of waxes isolated from a variety of crude oils. Energy Fuels. 1998;12:715-25. doi:10.1021/ef970206u.

Paso KG, Fogler HS. Bulk stabilization in wax deposition systems. Energy Fuels. 2004;18:1005-13. doi:10.1021/ef034105+.

Philp RP. High molecular weight paraffins $\left(>\mathrm{C}_{40}\right)$ in crude oils and source rocks. In: AAPG international conference, Mexico; 2004. p. 24-27.

Philp RP, Bishop A, del Rio J-C, Allen J. Characterization of high molecular weight hydrocarbons $\left(>\mathrm{C}_{40}\right)$ in oils and reservoir rocks. In: Cubitt JM, England WA, editors. Geochemistry of reservoirs. London: Geological Society Special Publication; 1995;86:71-85.

Schabron JF, Rovani JF, Sanderson MM, Loveridge JL, Nyadong L, McKenna AM, Marshall AG. Waxphaltene determinator method for automated precipitation and redissolution of wax and asphaltene components. Energy Fuels. 2012;26:2256-68. doi:10.1021/ef300184s.

Senra MJ. Assessing the role of polydispersity and cocrystallization on crystallizing $n$-alkanes in $n$-alkane solutions. Ph.D, Dissertation. University of Michigan; 2009.

Senra MJ, Panacharoensawad E, Kraiwattanawong K, Singh P, Fogler HS. Role of $n$-alkane polydispersity on the crystallization of $n$ alkanes from solution. Energy Fuels. 2008;22:545-55. doi:10. 1021/ef700490k.

Stachowiak C, Viguie J-R, Grolier J-PE, Rogalski M. Effect of $n$ alkane on asphaltene structuring in petroleum oils. Langmuir. 2005;21:4824-9. doi:10.1021/la047126k.

Strausz OP, Safarik I, Lown EM, Morales-Izquierdo AA. Critique of asphaltene fluorescence decay and depolarization-based claims about molecular weight and molecular architecture. Energy Fuels. 2008;22:1156-66. doi:10.1021/ef700320p.

Thanh NX, Hsieh M, Philp RP. Waxes and asphaltenes in crude oils. Org Geochem. 1999;30:119-32. doi:10.1016/S01466380(98)00208-3.

Tissot BP, Welte DH. Petroleum Formation and occurrence: a new approach to oil and gas exploration. Berlin: Springer; 1978.

Yang X, Kilpatrick P. Asphaltenes and waxes do not interact synergistically and coprecipitate in solid organic deposits. Energy Fuels. 2005;19:1360-75. doi:10.1021/ef050022c. 